\title{
Incidencia de la pobreza en Costa Rica entre 1987 y 2017: ¿estancamiento o reducción? ${ }^{1}$
}

\author{
Andrés Fernández Aráuz y Ronulfo Jiménez Rodríguez
}

\section{Resumen}

Según datos oficiales (basados en la línea de ingresos), la pobreza en Costa Rica llegó a afectar al 20\% de los hogares en 1994 y, aparentemente, no se habría alejado de forma sustancial de ese valor. En la actualidad se considera que el nivel de pobreza se encuentra estancado en torno al $20 \%$ desde hace más de dos décadas. Sin embargo, la medición de la pobreza ha sufrido cambios metodológicos que impiden la estricta comparación de los datos en el tiempo. En esta investigación se realiza una propuesta para superar las dificultades metodológicas y obtener una serie de datos de pobreza comparables en el período de 1987 a 2017, con la cual se demuestra que la pobreza en Costa Rica mostró pocas variaciones entre 1994 y 2006, pero se redujo a partir de este último año.

\section{Palabras clave}

Pobreza, ingresos, hogares, encuestas de hogares, mitigación de la pobreza, medición, metodología estadística, Costa Rica

\section{Clasificación JEL}

C13, C18, I3, P4

\section{Autores}

Andrés Fernández Aráuz es Licenciado en Economía y Máster en Estadística de la Universidad de Costa Rica. Correo electrónico: affa17@gmail.com.

Ronulfo Jiménez Rodríguez es Licenciado en Economía de la Universidad de Costa Rica. Correo electrónico: ronujimenez@gmail.com. 


\section{Introducción}

Si bien en Costa Rica se han utilizado varios métodos para medir la pobreza, la medición oficial es aquella realizada con el método de la línea de ingresos o línea de pobreza y publicada anualmente por el Instituto Nacional de Estadística y Censos (INEC)².

La medición del ingreso para estimar los niveles de pobreza realizada por el INEC se basa en la Encuesta de Hogares de Propósitos Múltiples (EHPM) desde 1976 hasta 2009 y en la Encuesta Nacional de Hogares (ENAHO) a partir de 2010.

Según datos oficiales, tras la crisis económica que afectó a Costa Rica a comienzos de la década de 1980, la pobreza disminuyó hasta alcanzar el 20\% de los hogares en 1994 y, aparentemente, no se habría alejado de forma sustancial de ese valor. En la actualidad se considera que la el nivel de pobreza se encuentra estancado en torno al 20\% desde hace más de dos décadas (véase el gráfico 1).

\section{Gráfico 1}

Costa Rica: cifras oficiales de pobreza y pobreza extrema, 1980-2017

(En porcentajes)

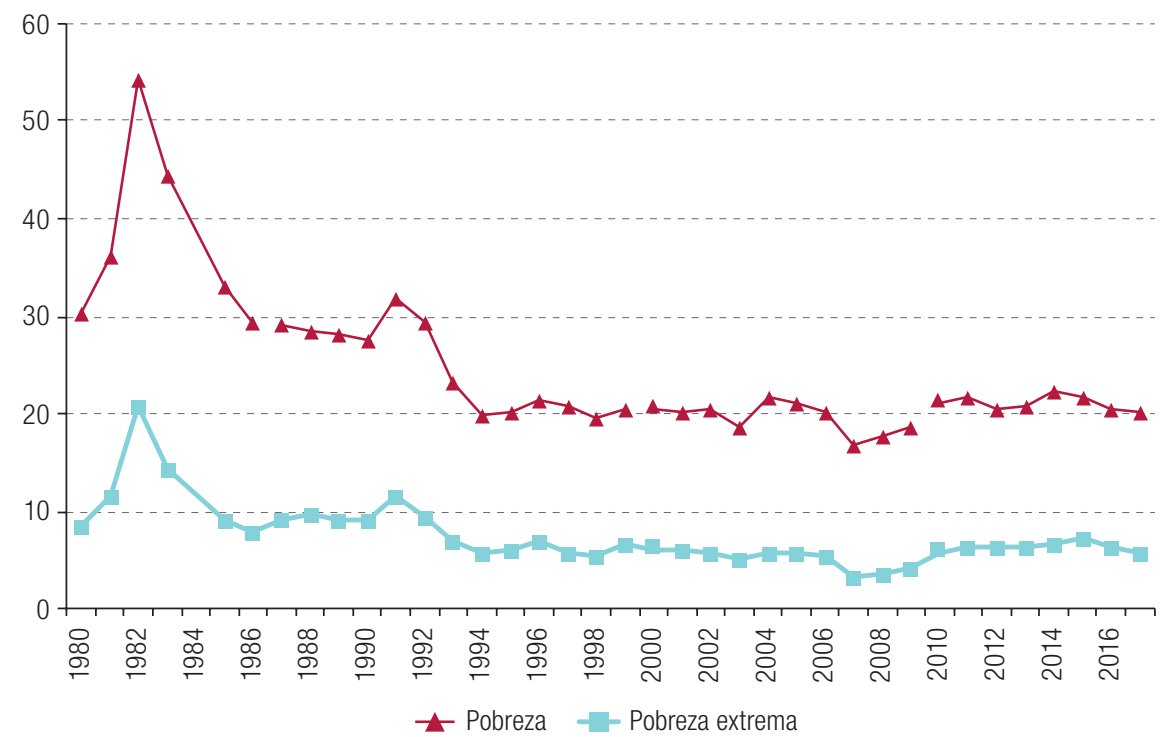

Fuente: P. Sauma, y J. Trejos, "Evolución de la pobreza en Costa Rica: una revisión de las estimaciones 1980-1998", La pobreza en Costa Rica, Instituto de Investigaciones en Ciencias Económicas (IICE), 2010, para el período de 1980 a 1986; Instituto Nacional de Estadística y Censos (INEC), Encuesta de Hogares de Propósitos Múltiples (EHPM), para el período de 1987 a 2009 y Encuesta Nacional de Hogares para el período de 2010 a 2017.

Sin embargo, el método oficial de medición de la pobreza en Costa Rica presenta cuatro grandes limitaciones desde el punto de vista de la comparabilidad de los datos (tres relacionadas con la medición del ingreso y una con la medición del valor de la línea de pobreza), que impiden el estudio de la evolución de la pobreza a largo plazo.

A menudo estas limitaciones se dejan de lado y, por el contrario, se habla sobre la evolución de la pobreza en los últimos 30 años como si se tratara de una serie comparable en el tiempo. Efectivamente, en los últimos años se han realizado con frecuencia afirmaciones sobre el estancamiento de la reducción de la incidencia de la pobreza como las siguientes:

\footnotetext{
2 Recientemente se ha incorporado una versión del índice de pobreza multidimensional en la medición oficial. Véase INEC (2015a, 2015b y 2018) y Fernández y Del Valle (2017 y 2016).
} 
- El enfoque según la línea de pobreza, o insuficiencia de ingresos, estima que, en promedio, una quinta parte de los hogares de Costa Rica es pobre. A partir de 1994 se inició un período de estancamiento que, con algunas variaciones en años específicos (como 2003 y 2007), mantiene el indicador en un 20\%. En 2016 se registró una incidencia de 20,5 (PEN, 2017, pág. 42).

- En Costa Rica, el porcentaje de hogares en condición de pobreza, según el método de línea de pobreza, se ha mantenido cercano al 20\% desde la última década [se refiere al período 2005-2015] (INEC, 2015b, pág. 9).

- La proporción de familias viviendo por debajo de la línea de pobreza cayó, a principios de los noventa, a un $20 \%$, pero desde entonces se ha mantenido relativamente estable con algunos altos y bajos. En 2013 la tasa de pobreza era de 20,7\% (Hidalgo, 2014).

Estas afirmaciones se sustentan en los datos de la medición oficial de la pobreza.

El objetivo de este trabajo consiste en superar esas limitaciones mediante la reconstrucción de la serie de ingreso per cápita del hogar para permitir la comparación entre los distintos años y la reconstrucción del valor de la canasta básica de alimentos y la línea de pobreza. Los resultados de este ejercicio son reveladores. Cuando la medición se realiza con una metodología comparable para todo el período, la afirmación de que la incidencia de la pobreza se estancó entre 1994 y 2017 es incorrecta. Según los resultados de esta investigación, es posible distinguir dos subperíodos. En el primero, que va de 1994 a 2006, se constata la existencia de un estancamiento de la incidencia de la pobreza, definida como porcentaje de hogares pobres con respecto al total de hogares del país. En el segundo, que va de 2006 a 2017, no solo disminuye la incidencia de la pobreza, sino que también se reducen la pobreza extrema y la proporción de hogares vulnerables.

Este artículo se divide en seis secciones, incluida esta introducción. Mientras en la segunda sección se explican todos los aspectos relacionados con la medición y el tratamiento de los ingresos en el marco de las encuestas de hogares del INEC de Costa Rica, en la tercera se describen la creación y la conformación de la canasta básica de alimentos y la línea de pobreza utilizadas en el país centroamericano. En la cuarta sección se explica la metodología aplicada para crear ocho series de pobreza comparables en el tiempo. En la quinta sección se muestran los resultados y en la sexta y última se presentan las conclusiones.

\section{La medición del ingreso y su tratamiento en las encuestas de hogares}

El método de la línea de pobreza requiere la medición del ingreso del hogar y el establecimiento de un umbral o línea para distinguir a los hogares pobres de aquellos que no lo son. En Costa Rica, la institución responsable de recolectar, procesar y publicar estos datos estadísticos es el INEC, a través de su encuesta de hogares.

Desde 1976, el INEC realiza una encuesta de hogares en el mes de julio para disponer de diversas estadísticas sobre la población y los hogares. Es la principal fuente de información sobre la incidencia de la pobreza, las condiciones de las viviendas y sus servicios, entre otros temas (INEC, 2010a y 2010b). A lo largo del tiempo, el INEC ha realizado cambios en la muestra, las definiciones de los conceptos y las formas de medir las diferentes variables, con miras a mejorar la medición y la captación de los fenómenos económicos y sociales y sus variaciones. Si bien esto es positivo, los cambios metodológicos pueden dificultar la comparación de los datos relativos a largos períodos de tiempo. 
En 2010 comenzó un nuevo ciclo del programa de encuestas de hogares, que se denomina Encuesta Nacional de Hogares (ENAHO) para resaltar el cambio con respecto a la Encuesta de Hogares de Propósitos Múltiples (EHPM) realizada hasta 2009. La ENAHO continúa siendo una encuesta multipropósito en la que prevalecen los temas de investigación básicos, incluidas las características sociodemográficas y de las viviendas, la condición de actividad, las características del empleo de las personas ocupadas, los ingresos derivados del trabajo y otras fuentes y la pobreza. Sin embargo, existen importantes diferencias en la recolección y el procesamiento de la información sobre el ingreso entre una y otra encuesta, que se detallan a continuación.

\section{Definición de los ingresos}

En general, la medición del ingreso constituye una tarea muy compleja. Mientras algunos componentes son fáciles de medir (salarios monetarios), otros plantean mayor dificultad (ingreso del trabajo independiente). Asimismo, algunos ingresos se reciben en forma regular y otros en forma esporádica, algunos se reciben en dinero y otros en especie.

Entre 1976 y 1979, en la EHPM de Costa Rica se investigaron únicamente los salarios. Posteriormente, en el período 1980-1986, se midió la renta primaria, es decir, los salarios y la renta empresarial (Sauma y Trejos, 2010). Las encuestas de hogares se modificaron nuevamente en 1987, cuando se incluyó una muestra más grande con respecto a la utilizada hasta ese momento y se modificó el cuestionario (instrumento de recolección de información) para adecuarlo a nuevas definiciones y cambios en la estrategia de captación de información. En el caso específico de los ingresos, a partir de 1987 se modificaron la definición y la forma de cálculo de la renta primaria y se comenzaron a estimar las transferencias percibidas por las familias. A partir de 1991 se comenzaron a medir los ingresos de capital.

Dadas las dificultades para tener una definición común desde 1976, el análisis de la pobreza que se plantea en este estudio se hace a partir de 1987. Al indagar sobre los ingresos, en la EHPM se mantuvo el mismo conjunto de preguntas durante 23 años (desde 1987 hasta 2009). La ENAHO (2010-2017), por otra parte, se diferencia de la EHPM por la investigación más amplia de los ingresos recibidos por concepto de trabajo asalariado, la diferenciación del ingreso independiente según el sector de actividad y la mayor especificación de rubros de ingresos provenientes de rentas de la propiedad y transferencias regulares (INEC, 2010b).

Claramente, la recolección de datos sobre los ingresos en una y otra encuesta ha sido muy distinta, por lo que el análisis del ingreso total (es decir, la suma de todos los ingresos) debe realizarse con extremo cuidado, pues muchos tipos de ingreso captados con la nueva ENAHO no figuraban en la antigua EHPM, e incluso algunos datos aparentemente recolectados en ambas encuestas no se obtenían mediante preguntas explícitas en la EHPM, sino que se consideraban implícitos en las respuestas proporcionadas por el hogar.

Los datos de la serie de ingresos del hogar 1987-2009 son bastante comparables en términos relativos, pues si bien hubo varios cambios relacionados con el marco muestral, los ponderadores y la estratificación, estos solo afectan las estimaciones de totales por zonas o regiones, mientras las estimaciones de números relativos (como los porcentajes) a nivel nacional son perfectamente comparables entre los distintos años. Así, el reto consiste en equiparar la medición de los ingresos de la nueva ENAHO con la antigua EHPM.

Actualmente, el ingreso total del hogar medido en la ENAHO comprende cinco grandes fuentes de ingresos, cada una de las cuales se divide en distintos subcomponentes. De las 47 categorías en que se puede descomponer la recolección de ingresos actual, solo 19 figuraban también en la antigua EHPM, e incluso no todas se analizaban de la misma forma. Así, es posible realizar el cálculo del ingreso de los hogares de 2010 a 2017, pero excluyendo aquellas categorías que no se abordaban 
directamente en la EHPM. Al hacer esto, evidentemente se obtendrá una reducción del ingreso total del hogar debido a la exclusión de las nuevas categorías de ingreso incluidas en la ENAHO.

En términos generales, a nivel nacional se mantiene el 88\% de los ingresos totales captados por la nueva ENAHO, es decir que el $12 \%$ de los ingresos actualmente captados desaparece para obtener una serie de ingresos comparable entre períodos. No obstante, la situación varía según la condición de ingresos inicial de cada hogar. Por ejemplo, en el caso de los hogares del décimo decil de ingresos, solo permanece el $85 \%$ de los ingresos totales, mientras en el de los hogares del primer decil de ingresos el dato aumenta al 95\%, lo que significa que la afectación es menor para los hogares con menores ingresos (debido a la menor diversificación de sus fuentes de ingresos). Esto indica que el cambio en los ingresos de los deciles más pobres es menor. Al no tomar en cuenta estos ingresos en el cálculo del ingreso total de los hogares, los niveles de pobreza estimados para cada año resultarán necesariamente afectados.

\section{Imputación de los ingresos faltantes}

Las estimaciones oficiales de pobreza derivadas de la EHPM (1987-2009) y de la ENAHO (2010-2017) no son comparables por el tratamiento de los ingresos faltantes o no declarados.

Las encuestas de hogares se aplican a una muestra representativa de las viviendas (y hogares) del país. Puede ocurrir que el entrevistador no pueda aplicar el cuestionario a un hogar determinado por no localizarse al informante o porque este se niegue a cooperar. En este caso, el hogar deberá reemplazarse por otro en el que se suministre la información. También puede ocurrir que el informante acepte la entrevista, pero no pueda o no quiera suministrar la información relativa al ingreso de algunos o de todos los miembros perceptores del hogar. En caso de perceptores con ingreso desconocido, el hogar se clasifica en la categoría "ingreso desconocido".

Entre 1987 y 2009, cuando esto sucedía en el marco de la EHPM y no se contaba con un ingreso efectivamente medido, el INEC calculaba los niveles de pobreza excluyendo a estos hogares, es decir, el método de la línea de pobreza se aplicaba solamente a los hogares con ingreso conocido. La práctica de excluir a los hogares con ingreso desconocido limita o impide las inferencias relativas al total de la población, a menos que se pueda establecer el supuesto (poco factible) de que la distribución de los datos faltantes es completamente aleatoria.

En el caso de la nueva ENAHO (2010-2017), los hogares con ingreso desconocido se toman en consideración mediante un método de imputación que permite asignar un nivel de ingreso a estos hogares (medias condicionadas). En la ENAHO, el porcentaje de hogares en los que al menos un miembro del hogar - perceptor de ingreso - no declara su ingreso ronda el 6\%. Si en esta encuesta se aplicara la metodología utilizada de 1987 a 2009 para estimar la pobreza pero excluyendo a los hogares con ingreso desconocido, los niveles de pobreza serían mayores con respecto a los oficialmente estimados en todos los años. Además, cuanto mayor sea el porcentaje de hogares con valores faltantes en sus ingresos, mayor será la diferencia entre la estimación de pobreza oficial y la no oficial (que excluye a esos hogares).

Esto se debe a que, de todos los hogares a los que se imputa al menos un tipo de ingreso, menos de la décima parte se clasifica en última instancia como pobre, de manera que cuantos más sean los hogares a los que haya que imputar el ingreso, menos pobres y más hogares no pobres se obtendrán proporcionalmente. Esta última idea debe interpretarse con sumo cuidado. El hecho de que la mayoría de los hogares a los que se imputa el ingreso en las bases de datos del INEC se clasifique como no pobre implica que, en general, son los miembros de los hogares con mayores recursos los que, al parecer, no declaran algunos de sus ingresos (dado que el método de imputación estima el nivel de ingreso para personas con características similares desde el punto de vista del sexo, el nivel de educación y la ocupación). Si este supuesto se mantuviera para el período 1987-2009, se podría concluir que las estimaciones oficiales de pobreza para esos años estarían sobrestimadas. En otras 
palabras, si se imputaran ingresos a los hogares donde hay valores faltantes (en lugar de excluirlos), el nivel de pobreza sería inferior en toda la serie. Mientras en la serie 1987-1993 se excluyó a una media del $20 \%$ de los hogares de las estimaciones de pobreza, esa proporción se redujo al $13 \%$ en los años 1994-2004 y al 7\% en el período 2005-2009.

Esto significa que la diferencia entre la incidencia de la pobreza estimada con la metodología oficial y aquella basada en la imputación de los ingresos ignorados no es constante a lo largo del período 1987-2017. Las estimaciones de incidencia de pobreza con imputación de ingresos desconocidos para el período 1987-1993 serían las que más disminuirían con respecto a la estimación oficial, mientras la serie 2005-2009 sería la que sufriría menos variaciones con respecto a la serie oficial.

Al realizar estas estimaciones se encontró evidencia que apoya lo expuesto: la diferencia en los niveles de pobreza oficiales con respecto a las cifras imputadas es del -15\% para el período 1987-1993, el -9,4\% en el período 1994-2004 y el -4,8\% en 2005-2009. Es por esta razón que, para uniformar metodológicamente la estimación de los ingresos de los hogares con respecto a los ingresos ignorados para todo el período 1987-2010, se aplicará el método de imputación de medias condicionadas utilizado en el período 2010-2017 a las EHPM de los años 1987 a 2009, según se explica en la sección relativa a la metodología.

\section{Subdeclaración de ingresos}

Si bien es posible que los hogares suministren la información relativa a los ingresos de todos los perceptores, en algunos casos los informantes tienden a subdeclarar el monto de los ingresos recibidos, es decir que, por diversos motivos, declaran ingresos inferiores a los efectivamente recibidos por el hogar. Por esta razón, al usar la información del ingreso procedente de una encuesta se plantea la disyuntiva de usar los montos de ingresos tal como fueron declarados - aún con la sospecha de que sean inferiores a los efectivamente percibidos - o ajustarlos para reducir o eliminar el efecto de dicha subdeclaración.

Tanto en la EPHM (1987-2009) como en la ENAHO (2010-2017), el INEC se ha inclinado por la segunda opción, es decir la realización de un ajuste multiplicando los ingresos declarados por un coeficiente. Sin embargo, el criterio para realizar el ajuste ha sido diferente en ambos períodos. En la EHPM (1987-2009), el INEC ajustaba los ingresos per cápita de los hogares urbanos y rurales en forma diferenciada. El ingreso declarado se multiplicaba por un coeficiente de 1,174 en el caso de los hogares de zonas urbanas y de 1,358 en el de los hogares ubicados en zonas rurales (INEC, 2002). Es decir, el nivel de ingreso per cápita de cada hogar se incrementaba entre un 17\% y un 35\%, para finalmente calcular el nivel de pobreza de la población (INEC, 2004). En la ENAHO (2010-2017), los coeficientes se obtienen comparando los ingresos estimados con el Sistema de Cuentas Nacionales del Banco Central por fuente de ingreso. En particular, se ajustan los siguientes tipos de ingreso (INEC, 2018): i) salario agropecuario (coeficiente de 1,59); ii) salario no agropecuario $(1,30)$; iii) ingreso independiente agropecuario (1,60); iv) ingreso independiente no agropecuario $(1,30)$; v) ingreso por renta de la propiedad $(2,08)$. El resto de los ingresos (no mencionados) no se ajusta.

No solo los valores de los coeficientes son distintos, sino también su aplicación por zona y tipos de ingreso: mientras antes de 2010 el ingreso per cápita se ajustaba con un único coeficiente según el tipo de hogar, de manera que a todos los tipos de ingreso se aplicaba el mismo coeficiente, a partir de ese año el ajuste ya no se aplica al ingreso per cápita, sino a cada tipo de ingreso por separado y no a todos los tipos de ingreso. A priori, no es posible saber cuál de las dos metodologías determina el mayor ajuste de los ingresos, ya que si bien los nuevos coeficientes aplicados en la ENAHO son mayores con respecto a los utilizados anteriormente, solo se aplican a algunos tipos de ingreso (por ejemplo, no se ajustan las transferencias), mientras en la EHPM el coeficiente se aplicaba implícitamente a todos los tipos de ingreso (mediante el ingreso per cápita). 
En conclusión, los ajustes por subdeclaración determinan la imposibilidad de comparar la medición del ingreso y la incidencia de la pobreza entre ambos períodos. Por ese motivo, en este estudio se utilizan alternativamente dos series de ingresos. Una de ellas se ajusta para todo el período 1987-2017 según el criterio aplicado en el período 1987-2009 en cuanto a la subdeclaración de ingresos. Dado que no es posible ajustar los ingresos de todo el período con el criterio aplicado entre 2010 y 2017, porque la desagregación de la información en las bases de datos para el período 1987-2009 no lo permite, la otra serie no se somete a ningún ajuste por subdeclaración, es decir que incluye los ingresos tal como fueron declarados por los informantes.

\section{Líneas de pobreza}

Como ya se mencionó, la medición de la pobreza según el método de la línea de pobreza requiere la comparación del ingreso del hogar con un umbral o línea mínima para clasificar los hogares como pobres o no pobres.

En esta sección se analizan los criterios aplicados por el INEC en la metodología oficial para medir la canasta básica de alimentos y la línea de pobreza en el período 1987-2017 y se realiza una propuesta para lograr una medición uniforme de estos conceptos y permitir la comparación en el período señalado.

\section{Línea de pobreza y canasta básica de alimentos}

El concepto básico de línea de pobreza es uno de los más antiguos de la economía aplicada, pues se conoce al menos desde el siglo XVIII (Ravallion, 2016). Incluso antes del establecimiento de medidas de pobreza para fines descriptivos, ya se había intentado definir un nivel mínimo de ingreso para no ser considerado pobre para fines de política.

La concepción aplicada de la pobreza ha variado desde los conceptos de bienestar o utilidad hasta la medición del producto interno bruto (PIB) como parámetro sustitutivo (proxy). No obstante, la disponibilidad de mediciones robustas de pobreza según distintos criterios se remonta solo a unas pocas décadas. Si bien esto ha determinado la existencia de varias formas muy distintas de medir la pobreza en la literatura especializada, esta investigación se centra en la medición más utilizada a nivel mundial, basada en los ingresos de los hogares y denominada método de la línea de pobreza.

La definición económica de línea de pobreza es "el costo de obtener un nivel determinado de bienestar económico o de estándar de vida en un lugar y período determinado" (Ravallion, 2016). Esta definición depende del índice de costo de vida (o canasta básica de alimentos) que se utilice para definir el nivel de bienestar o estándar de vida de referencia.

La idea clave de las líneas de pobreza es que la referencia representa el nivel mínimo de bienestar económico necesario para no ser considerado pobre. En Costa Rica, el método oficial supone el cálculo de una línea de pobreza que representa el monto mínimo de ingresos que permite a un hogar disponer de recursos suficientes para atender las necesidades básicas de sus miembros (INEC, 2004).

En el período 1987-2017 se utilizaron dos canastas básicas de alimentos y, en consecuencia, dos líneas de pobreza. La primera, denominada CBA-1995, se utilizó para el período 1987-2009, y la segunda, denominada CBA-2011, entre 2010 y 2017. Si bien la metodología de ambas líneas de pobreza es similar en términos generales, algunos detalles implican diferencias en la construcción de ambas. Por ejemplo, mientras la CBA-1995 se construyó en 1995 sobre la base de la estructura de gastos de los hogares de 1988, la CBA-2011 se construyó en 2011 a partir de la estructura de gastos y consumo de los hogares de 2004. Además, la CBA-2011 comprende una mayor cantidad de 
alimentos que la CBA-1995, aunque paradójicamente da cuenta de una menor cantidad de calorías mínimas requeridas (2.184 con respecto a 2.230 en las zonas urbanas).

El INEC calculó el valor de la CBA-2011 desde 2004, pues su construcción se basó en la Encuesta Nacional de Ingresos y Gastos de los Hogares (ENIGH) de ese año. Esto permitió comparar la canasta básica de alimentos y la línea de pobreza establecidas con ambas metodologías para los años 2004-2009. Se observa que los valores de la canasta básica de alimentos y la línea de pobreza basadas en la metodología de 2011 son más altos con respecto a 1995. En otras palabras, el cambio metodológico supone umbrales más exigentes para definir cuáles hogares son pobres y cuáles no lo son. En promedio, en el período 2004-2009, el costo de la CBA-2011 con respecto a la CBA-1995 fue un 13\% mayor en las zonas urbanas y un $7 \%$ mayor en las zonas rurales. Estos cambios se reflejan en mayor medida en el valor de la línea de pobreza, porque la metodología de 2011 supuso la aplicación de coeficientes más altos para pasar de la canasta básica de alimentos a la línea de pobreza ${ }^{3}$. Con la metodología de 2011, la línea de pobreza aumentó un 37\% en las zonas urbanas y un 25\% en las zonas rurales en comparación con la metodología de 1995.

Es importante recordar la necesidad de que el INEC realizara el cambio metodológico para actualizar la definición de los umbrales de pobreza. Como era de esperar, dada la mejora en las condiciones generales de vida del país, esto implicaba valores monetarios más altos en la canasta básica de alimentos y la línea de pobreza según la nueva metodología en comparación con la anterior. Si bien la estimación oficial del INEC de la incidencia de la pobreza en el período 2004-2009 se basó en su momento en la CBA-1995, es evidente que al utilizar la CBA-2011 para esos mismos años las estimaciones de incidencia de la pobreza serían mayores. En otras palabras, el cambio metodológico tiene consecuencias en el nivel estimado de pobreza y no permite la comparación de dos períodos en los cuales la metodología de estimación de la canasta básica de alimentos y la línea de pobreza son diferentes.

En conclusión, para medir la pobreza en el período 1987-2017 se han utilizado dos canastas distintas, cada una de las cuales refleja el patrón de consumo imperante en el año en que fue captada. Esta diferenciación se traduce en la estimación de diferentes niveles de pobreza en el país. Para obtener una única serie de datos comparables del valor de la canasta básica de alimentos y la línea de pobreza en todo el período se podría optar por tomar la CBA-1995, mantener su composición y continuar su valoración con los precios observados en el período 2010-2017 o tomar la CBA-2011, mantener su composición y estimar su valor con los precios observados entre 1987 y 2009. Lamentablemente, ambas opciones son inviables, porque los datos relativos a algunos bienes de la antigua canasta dejaron de recolectarse después del cambio metodológico o porque los precios de algunos bienes de la nueva canasta no se recolectaban antes de este.

Dada esta imposibilidad, otra vía consiste en "empalmar" el valor de ambas canastas mediante el crecimiento del valor corriente de ambas. Para esto es importante indagar si sufrieron variaciones similares en un período para el cual se dispone de la estimación del valor de ambas canastas simultáneamente, es decir entre 2004 y 2009. En esos años no se observan grandes diferencias en las tendencias, sino más bien una gran similitud en los valores de algunos años. Esto significa que, aunque la estructura y la composición de la canasta básica de alimentos sean distintas entre la serie CBA-1995 y la serie CBA-2011, el crecimiento relativo de los precios de los bienes y servicios dentro de cada canasta ha sido similar. Si se asume el mismo comportamiento para los demás años de la serie temporal analizada en este documento, es posible simular el valor de la CBA-1995 en el período 2010-2017 y el valor de la CBA-2011 en el período 1987-2003, con lo cual se podrían obtener dos series de pobreza a largo plazo, comparables a lo largo del tiempo.

\footnotetext{
3 En la CBA-1995, el INEC aplicó el coeficiente de Engel para calcular el valor de la línea de pobreza, mientras en la CBA-2011 utilizó el coeficiente de Orshansky. Este último es el inverso del coeficiente de Engel, que mide la proporción del gasto en alimentos dentro del gasto total.
} 


\section{Metodología}

El objetivo de esta sección es construir una serie de datos comparables sobre la evolución de la pobreza en Costa Rica en el período 1987-2017. Para ello se parte de la serie oficial y se realizan los ajustes necesarios para poder comparar las distintas medidas del ingreso y la línea pobreza y así superar las limitaciones de comparabilidad señaladas en las secciones anteriores.

Como se mencionó anteriormente, las estimaciones de pobreza realizadas por el INEC desde 1987 hasta 2017 no son estrictamente comparables en varios subperíodos, debido a los cambios en la medición de los ingresos (definición de ingresos, tratamiento de los ingresos desconocidos y ajustes por subdeclaración de ingresos) y en la composición y la valoración de la canasta básica de alimentos y la línea de pobreza. Estos cambios se resumen en el cuadro 1.

\section{Cuadro 1}

Costa Rica: principales cambios en la metodología del Instituto Nacional de Estadística y Censos (INEC) para la medición de la pobreza

\begin{tabular}{lll}
\hline Factores que impiden la comparación & $\begin{array}{l}\text { Encuesta de Hogares de Propósitos } \\
\text { Múltiples (EHPM), 1987-2009 }\end{array}$ & $\begin{array}{l}\text { Encuesta Nacional de Hogares } \\
\text { (ENAH0), 2010-2017 }\end{array}$ \\
\hline Con respecto a los ingresos & & Se monetizan 47 tipos de ingreso \\
\hline Medición de ingresos del hogar & Se monetizan 19 tipos de ingreso & Se imputan (se incluyen) \\
\hline $\begin{array}{l}\text { Tratamiento de hogares con } \\
\text { ingreso desconocido }\end{array}$ & No se imputan (se excluyen) & Se aplica a algunos tipos de ingreso (no \\
\hline Ajuste por subdeclaración de ingresos & $\begin{array}{l}\text { Se aplica al ingreso per cápita } \\
\text { (todos los ingresos) y con distinción } \\
\text { entre zonas urbanas y rurales }\end{array}$ & todos) y distinción entre zonas \\
\hline $\begin{array}{l}\text { Con respecto a la canasta básica de alimentos y la línea de pobreza } \\
\text { Valor de la canasta básica de } \\
\text { alimentos y la línea de pobreza }\end{array}$ & $\begin{array}{l}\text { Se utiliza la canasta básica de alimentos } \\
\text { de 1995 (Encuesta Nacional de Ingresos }\end{array}$ & $\begin{array}{l}\text { Se utiliza la canasta básica de } \\
\text { alimentos de 2011 (ENIGH 2004) }\end{array}$ \\
\hline
\end{tabular}

Fuente: Elaboración propia.

El objetivo de esta investigación es estimar una serie de datos de pobreza a largo plazo en Costa Rica que sea comparable en todos sus extremos. Para ello, en las secciones anteriores se analizaron los factores que impiden la comparabilidad y se propusieron distintos métodos para superar esas limitaciones y observar la evolución de la pobreza en el tiempo.

Debido a que el objetivo es analizar la tendencia de la pobreza y no los niveles, se estimarán ocho series de pobreza según la combinación de factores que garantizan estandarización y comparabilidad para todo el período analizado, según se detalla en el cuadro 2.

Cuadro 2

Detalle de la construcción de ocho series de pobreza comparables a largo plazo

\begin{tabular}{|c|c|c|c|c|}
\hline $\begin{array}{l}\text { Serie de pobreza } \\
\text { reconstruida }\end{array}$ & Estructura de ingresos & Imputación & $\begin{array}{l}\text { Valor de la canasta básica de } \\
\text { alimentos y la línea de pobreza }\end{array}$ & $\begin{array}{l}\text { Ajuste por subdeclaración } \\
\text { de ingresos }\end{array}$ \\
\hline Serie de pobreza 1 & \multirow{8}{*}{$\begin{array}{l}\text { Encuesta de Hogares } \\
\text { de Propósitos } \\
\text { Múltiples (EHPM) }\end{array}$} & \multirow{4}{*}{$\begin{array}{l}\text { No se imputa } \\
\text { (según la EHPM) }\end{array}$} & \multirow{2}{*}{$\begin{array}{l}\text { CBA-1995 (Encuesta Nacional } \\
\text { de Ingresos y Gastos de los } \\
\text { Hogares (ENIGH) 1988) }\end{array}$} & No ajustar \\
\hline Serie de pobreza 2 & & & & Ajustar según la EHPM \\
\hline Serie de pobreza 3 & & & \multirow[t]{2}{*}{ CBA-2011 (ENIGH 2004) } & No ajustar \\
\hline Serie de pobreza 4 & & & & Ajustar según la EHPM \\
\hline Serie de pobreza 5 & & \multirow{4}{*}{$\begin{array}{l}\text { Se imputa (según la } \\
\text { Encuesta Nacional de } \\
\text { Hogares (ENAHO)) }\end{array}$} & \multirow[t]{2}{*}{ CBA-1995 (ENIGH 1988) } & No ajustar \\
\hline Serie de pobreza 6 & & & & Ajustar según la EHPM \\
\hline Serie de pobreza 7 & & & \multirow[t]{2}{*}{ CBA-2011 (ENIGH 2004) } & No ajustar \\
\hline Serie de pobreza 8 & & & & Ajustar según la EHPM \\
\hline
\end{tabular}

Fuente: Elaboración propia. 
Como se puede observar, solo se podrá utilizar la serie de ingresos con la estructura de ingresos de la EHPM, es decir, ajustar a la baja los ingresos de la ENAHO (lo que aumenta la pobreza en el período 2010-2017). A su vez, se aplicarán ambos métodos para el tratamiento de los ingresos desconocidos (no imputarlos e imputarlos).

Para imputar los ingresos se recurre al método de medias condicionadas, que consiste en formar categorías a partir de covariables correlacionadas con la variable de interés e imputar los datos omitidos con observaciones provenientes de la submuestra que comparte características comunes (Acock y Demo, 2005; Medina y Galván, 2007). En este método se asume que los datos faltantes siguen un patrón completamente aleatorio (missing completely at random (MCAR)) y existirán tantos promedios como categorías se formen. Esto contribuye a atenuar los sesgos en cada celda. En este caso específico, las variables condicionantes utilizadas en el proceso de imputación son las siguientes: "zona de residencia", "sexo", "escolaridad” y "ocupación”. La imputación se realiza sobre el ingreso principal, el ingreso secundario y los otros ingresos del hogar.

Se simularán los niveles de pobreza con las condiciones anteriores y según las dos series de valores de la canasta básica de alimentos reconstruidas con y sin ajuste por subdeclaración de ingresos. Todo esto permitirá obtener ocho series de pobreza distintas entre sí, pero constituidas por valores comparables metodológicamente a lo largo del período.

El objetivo es analizar la tendencia a largo plazo de estas ocho series de pobreza para determinar si la incidencia de la pobreza en Costa Rica se ha estancado o ha variado en las últimas tres décadas. Dado que no se trata de una serie de tiempo estacionaria (la autocorrelación serial es significativamente positiva), para comprender si las tendencias obtenidas con las series de pobreza estimadas son distintas con respecto a la serie oficial, se recurre al método de comparación de las pendientes de las rectas de regresión predichas según el cómputo de una regresión lineal bivariada.

Esta regresión estima la pendiente del modelo $P_{t}=\beta_{0}+\beta_{1} A_{t}+\varepsilon$, donde $P_{t}$ es el porcentaje de pobreza en el año "t", $\beta_{0}$ es el intercepto de la recta de regresión, $\beta_{1}$ es el valor de la pendiente de la recta sobre el año $A_{t}$ y $\varepsilon$ es un término de error. La estimación del modelo se realiza sobre variables estandarizadas, para obtener coeficientes estandarizados como medida de tamaño de efecto y de comparación entre los distintos modelos.

\section{Resultados}

Si bien el período analizado va de 1987 a 2017 (31 años de observaciones), algunos especialistas sostienen que el nivel de pobreza (según la medición oficial por línea de ingresos) se ha mantenido relativamente invariado a partir de 1994. Esto se traduce a menudo en afirmaciones como "la pobreza se ha estancado en torno al 20\%" o "la pobreza se ha mantenido estancada en las últimas dos décadas". Es de esperar que los cambios metodológicos implementados en el período de estudio afecten el nivel de la pobreza y su tendencia a largo plazo porque, como se ha demostrado en las secciones anteriores, las consideraciones metodológicas tienen importantes efectos en la medición de los ingresos, la canasta básica de alimentos y la línea de pobreza.

Mediante la aplicación de la metodología descrita en la sección anterior, se obtiene la estimación de ocho series de pobreza distintas entre sí, pero constituidas por valores comparables desde el punto de vista metodológico, que permiten analizar la evolución de la pobreza en el período 1987-2017.

Si bien no es posible comparar los valores individuales, es posible comparar las tendencias observadas a partir de estas estimaciones con la que surge de las cifras de pobreza oficiales estimadas por el INEC. Dado que no se trata de una serie de tiempo estacionaria (la autocorrelación serial es significativamente positiva), para comprender si las tendencias obtenidas con las series de pobreza 
estimadas son distintas con respecto a la serie oficial, se recurre al método de comparación de las pendientes de las rectas de regresión predichas según el cómputo de una regresión lineal, pero mostrando dicha pendiente como el coeficiente estandarizado obtenido del ajuste de dicha regresión acompañado de su significancia estadística (valor p), así como el valor de bondad de ajuste (R cuadrado) de ese modelo bivariado, pero tomando en consideración solo el período 1994-2017, ya que es a partir de 1994 que se considera que la pobreza no ha mostrado mejoras sustanciales.

Para comprender mejor el procedimiento, a continuación se muestra el valor de la pendiente y de R cuadrado para la serie oficial de pobreza estimada por el INEC para el período 1994-2017 (véase el gráfico 2).

\section{Gráfico 2}

Costa Rica: incidencia de la pobreza estimada por el INEC (oficial)

y pendiente de la recta de regresión, 1994-2017

(En porcentajes)

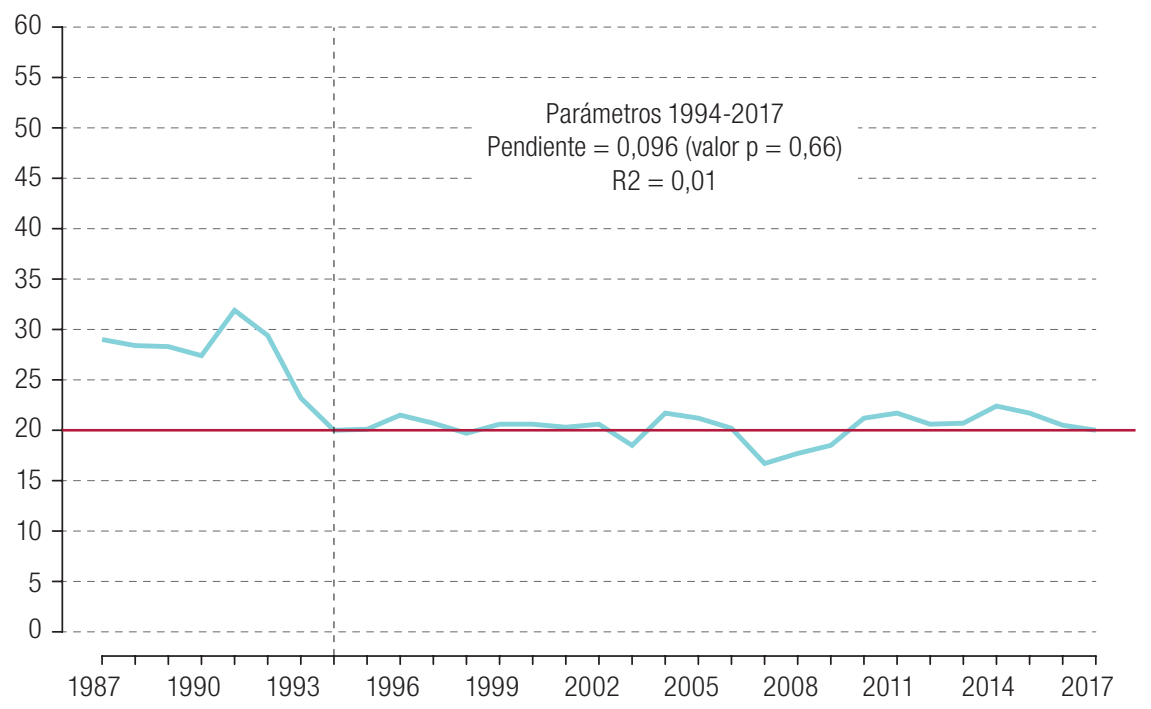

Fuente: Elaboración propia, sobre la base de datos del Instituto Nacional de Estadística y Censos (INEC) de Costa Rica.

Como puede observarse en el gráfico 2, entre 1994 y 2017 la incidencia de la pobreza no se aleja significativamente del 20\% (línea roja horizontal).

Al estimar una regresión lineal bivariada se observa que la pendiente de la serie de pobreza de 1994 a 2017 no es distinta de 0 desde el punto de vista estadístico, pues el estadístico de Wald es muy superior a los valores 0,01, 0,05 y 0,10 que suelen utilizarse como parámetros de comparación. Esto significa que, efectivamente, al analizar la serie de tiempo de pobreza oficialmente estimada por el INEC desde 1994 hasta 2017, sin tener en cuenta la imposibilidad de comparar los datos que la conforman, se observa que esta no ha variado en el tiempo, es decir, ha permanecido "estancada" en los últimos 23 años. Este tipo de análisis constituye el error que se intenta subsanar con esta investigación. Siguiendo esta misma lógica, a continuación se muestran las series de pobreza estimadas en esta investigación (véanse el gráfico 3 y los datos numéricos en el anexo A1). 


\section{Gráfico 3}

Costa Rica: series de pobreza estimadas y comparables para el período 1987-2017

(En porcentajes)

\section{A. Serie de pobreza 1}

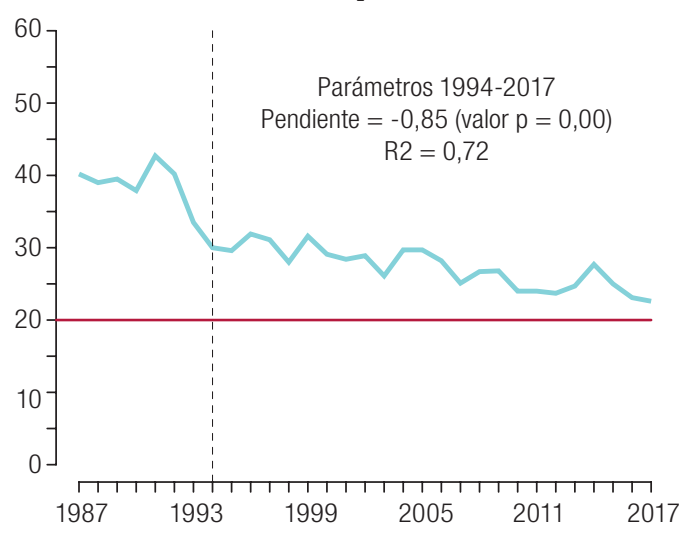

\section{Serie de pobreza 3}

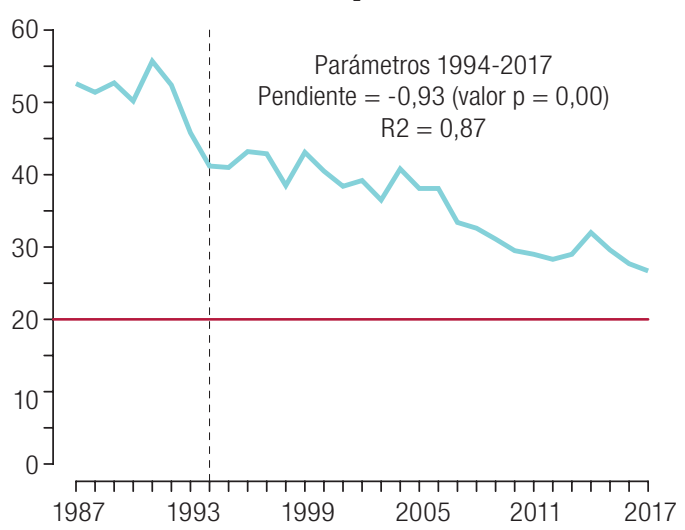

\section{E. Serie de pobreza 5}

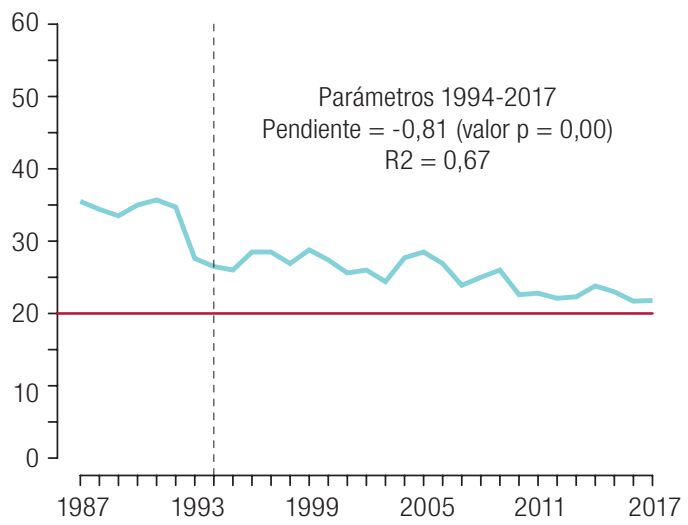

B. Serie de pobreza 2

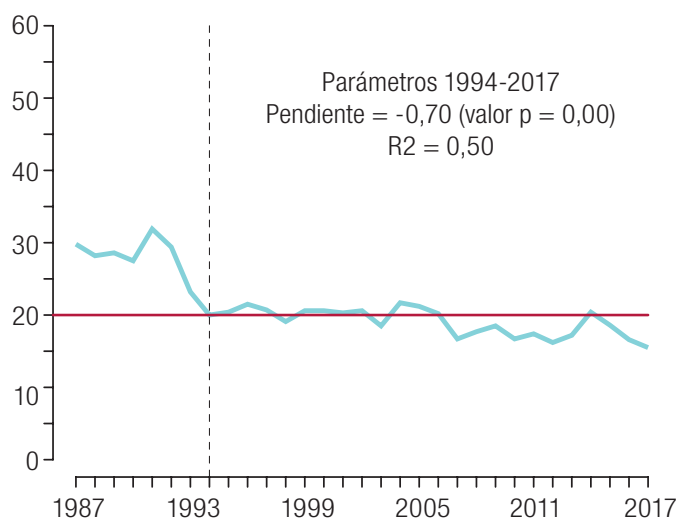

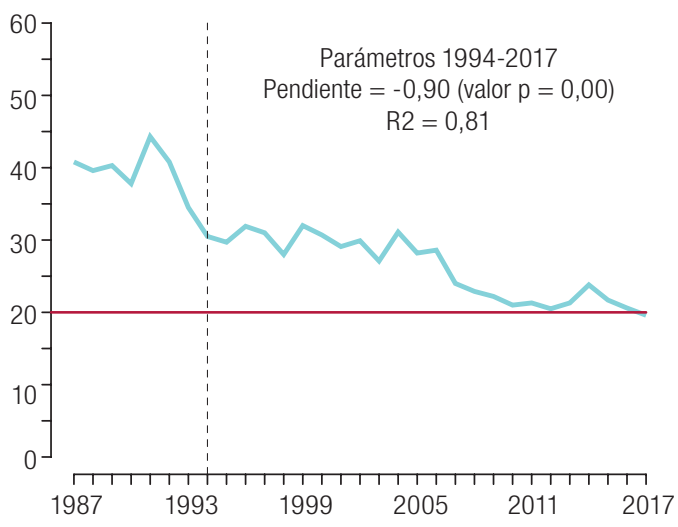

\section{F. Serie de pobreza 6}

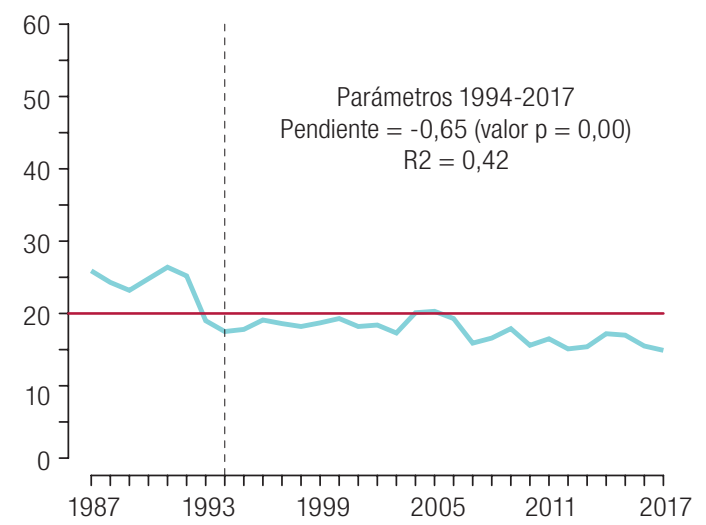


G. Serie de pobreza 7

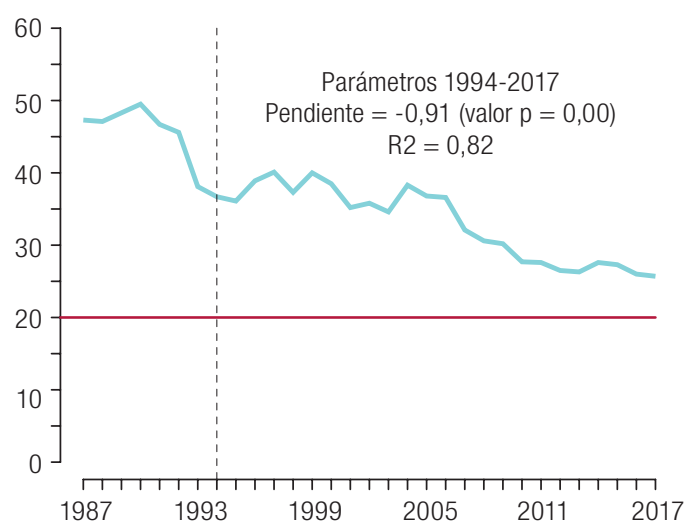

H. Serie de pobreza 8

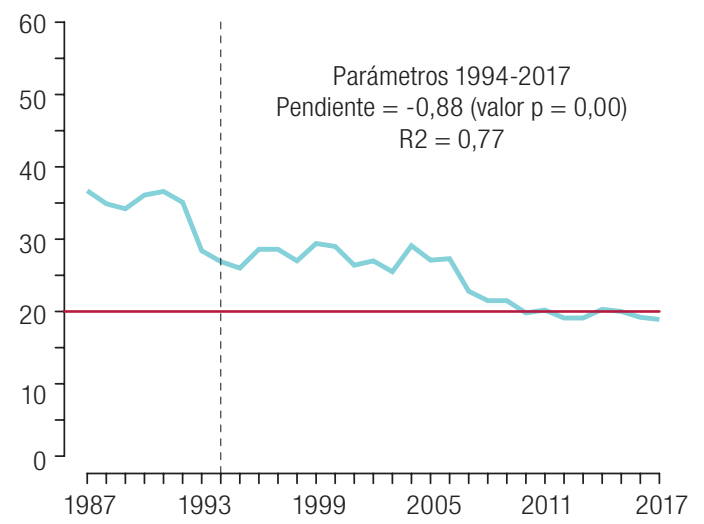

Fuente: Elaboración propia, sobre la base de datos del Instituto Nacional de Estadística y Censos (INEC) de Costa Rica.

En el gráfico 3 se muestra la evolución de la pobreza en Costa Rica entre 1994 y 2017 conforme las ocho series estimadas. Visualmente, se aprecia una tendencia decreciente en los ocho paneles y, estadísticamente, esta tendencia se confirma al observar que la pendiente de la recta de regresión estimada para cada una de las ocho series es negativa, estadísticamente distinta de 0 (valor p inferior a 0,01 ) y con un efecto considerable, pues los coeficientes estandarizados solo pueden variar entre 0 y 1 (valor absoluto) y para cuatro de las series de tiempo estimadas las pendientes estimadas son superiores a 0,75 (valor absoluto).

Este resultado muestra que, al utilizar series de pobreza basadas en datos comparables en el tiempo, se aprecia una reducción de la pobreza en los últimos 30 años, incluido el período que ha generado la mayor cantidad de críticas (a partir de 1994).

Una vez más, es importante tener presente que cada una de estas ocho series es distinta con respecto a las otras, pues todas ellas se basan en la combinación de los parámetros que inicialmente determinaban la imposibilidad de comparar los datos de la serie oficial. Sin embargo, los datos que las conforman son efectivamente comparables dentro de cada serie, pues se aplica la misma metodología a lo largo de todo el período.

En conclusión, la pobreza en Costa Rica se ha reducido en el período 1994-2017, como evidencia el análisis mediante series de datos comparables de ingreso, canasta básica de alimentos, ajuste por subdeclaración e imputación de ingresos. Sin embargo, un estudio aún más detallado de los datos permite observar distintos patrones en los 31 años de análisis. Dadas las variaciones de la pobreza en las ocho series, es posible distinguir cuatro subperíodos, tomando como referencia el registro de cambios significativos en los porcentajes de pobreza. De esta forma, se observan comportamientos similares en los años comprendidos en cuatro subperíodos, a saber: 1987-1992, 1992-1994, 1994-2006 y 2006-2017.

Para comprender lo que ocurrió en esos subperíodos, se reproduce exactamente el análisis anterior, estimando regresiones bivariadas y analizando el valor del coeficiente estandarizado de la regresión (la magnitud del efecto) y la significancia estadística de dicho coeficiente. Estos resultados se muestran en el anexo A2. La conclusión principal es que antes de 1994 hubo un primer período de estancamiento de la pobreza (1987-1992), seguido de una marcada disminución que duró solo dos años (1992-1994). En 1994 comienza un nuevo período de estancamiento que se prolonga por 12 años, mientras en 2006 inicia un período de reducción sostenida de la pobreza hasta 2017.

Esto significa que la reducción de la pobreza en el período 1994-2017 se debió sobre todo a la influencia de lo ocurrido entre 2006 y 2017, pues no se registraron grandes variaciones en la tendencia entre 1994 y 2006. 


\section{Breve caracterización de los hogares según la condición de pobreza}

Para estudiar más a fondo la evolución de la pobreza, se dividió a la población en cuatro grupos a fin de examinar sus características principales. Estos grupos corresponden a los hogares en situación de pobreza extrema, pobreza no extrema, hogares vulnerables y no pobres. El análisis se basa en una de las series de datos de pobreza comparables incluidas en el cuadro 2 (la serie 8).

Los hogares en situación de pobreza extrema son los que tienen un nivel de ingreso per cápita ajustado inferior al valor de la canasta básica de alimentos de 2011 reconstruida. Los hogares en situación de pobreza no extrema tienen un ingreso per cápita superior al valor de la canasta básica de alimentos de 2011 reconstruida pero inferior o igual al valor de la línea de pobreza de 2011 reconstruida. Por último, los hogares vulnerables son aquellos que no son pobres pero cuyo ingreso es, a lo sumo, un $30 \%$ mayor con respecto al valor de la línea de pobreza correspondiente, de manera que eventualmente podrían ingresar al grupo de hogares pobres.

En el gráfico 4 se muestra que en los años posteriores a la crisis de los años ochenta, específicamente en 1987, la pobreza afectaba al 37\% de los hogares del país, pero al tener en cuenta a los hogares en situación de vulnerabilidad, esa proporción aumenta al 48,5\%. En otras palabras, casi la mitad de los hogares del país estaba en situación de pobreza o muy cerca de estarlo.

\section{Gráfico 4}

Costa Rica: clasificación de los hogares según la condición de pobreza (serie 8), años seleccionados

(En porcentajes)

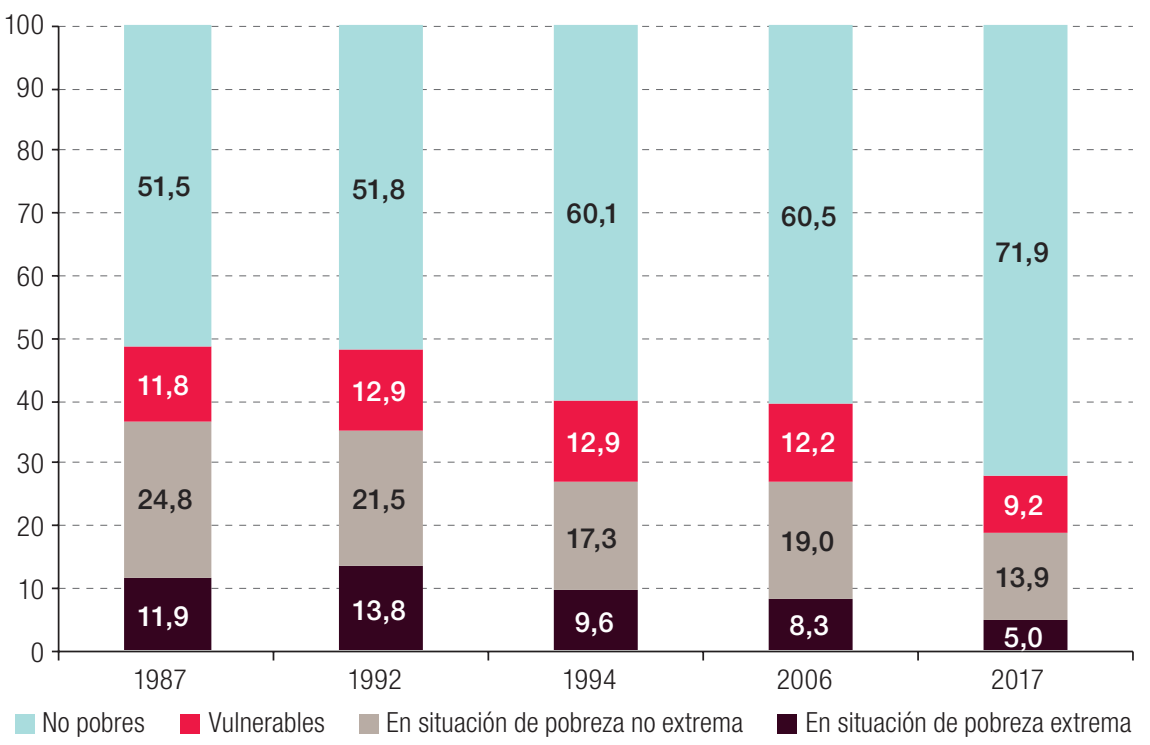

Fuente: Elaboración propia, sobre la base de datos del Instituto Nacional de Estadística y Censos (INEC) de Costa Rica.

En el período 1987-1992 no hubo cambios significativos en la clasificación de la estructura de los hogares según su condición de pobreza.

Entre 1992 y 1994, un período de tan solo dos años, la proporción de hogares en situación de pobreza extrema y pobreza no extrema se redujo (4,2 puntos porcentuales en cada caso). Si bien las causas de esta reducción tan drástica han sido poco estudiadas, se cree que está asociada a un fuerte crecimiento del ingreso nacional, que fue superior al $6 \%$ anual. 
En el período 1994-2006 no se registraron cambios sustanciales en la incidencia de la pobreza, de pobreza extrema o vulnerabilidad. En este período, en general, el crecimiento del ingreso nacional estuvo por debajo del $4 \%$.

En el período 2006-2017 se observa una reducción de la incidencia de la pobreza, pues disminuye la proporción de hogares en situación de pobreza extrema, pobreza no extrema y vulnerabilidad y, por ende, aumenta la proporción de hogares no afectados por la pobreza (véase el gráfico 4). La pobreza se redujo sobre todo en 2007, cuando el crecimiento del ingreso nacional fue superior al 6\%.

Así las cosas, en 2017 el nivel de pobreza en Costa Rica era un 48\% inferior con respecto a 1987 o, si se compara con la década de 1990 (cuando comenzó el llamado "estancamiento de la pobreza"), el país era un $30 \%$ menos pobre que en 1994. Sin lugar a dudas, este logro adquiere mayor importancia cuando se tiene en cuenta que la mayor reducción corresponde a los hogares en situación de pobreza extrema, cuya proporción en 2017 era menos de la mitad de la registrada en 1987.

En cuanto a la incidencia de la pobreza entre distintas subpoblaciones, uno de los principales enfoques se concentra en las diferencias según el sexo del jefe del hogar. Cabe señalar que, si bien la mayoría de los hogares pobres está encabezada por hombres (el 80\% en 1987 y el 54\% en 2017), la pobreza afecta en mayor medida a los hogares encabezados por mujeres y, en particular, a los hogares encabezados por mujeres que no tienen un compañero (jefas de hogar sin pareja).

Mientras el nivel de pobreza estimado en 2017 rondaba el 18\% a nivel nacional, esta proporción aumentaba al $24 \%$ en el caso de las mujeres jefas de hogar sin pareja. Esta tendencia se observa durante todo el período examinado (véase el cuadro 3).

\section{Cuadro 3}

Costa Rica: incidencia de la pobreza en distintas categorías de hogares, 1987-2017

$$
\text { (En porcentajes) }
$$

\begin{tabular}{lrrrrr}
\hline Característica & 1987 & 1992 & 1994 & 2006 & 2017 \\
\hline Sexo del jefe del hogar y situación conyugal & & & & & \\
\hline Hombre (con pareja) & 68,1 & 69,1 & 70,8 & 61,6 & 46,2 \\
\hline Hombre (sin pareja) & 12,2 & 10,2 & 8,5 & 5,9 & 8,4 \\
\hline Mujer (con pareja) & 1,1 & 2,4 & 1,9 & 3,2 & 8,2 \\
\hline Mujer (sin pareja) & 18,7 & 18,4 & 18,8 & 29,3 & 37,3 \\
\hline Grupo de edad del jefe del hogar & & & & & \\
\hline Menos de 40 años (joven) & 35,4 & 39,1 & 30,0 & 30,3 & 21,5 \\
\hline De 40 a 60 años (intermedio) & 31,3 & 32,2 & 23,7 & 24,0 & 16,8 \\
\hline 60 años o más (mayor) & 40,6 & 40,6 & 34,5 & 33,8 & 19,6 \\
\hline Región de planificación & & & & & \\
\hline Central & 29,5 & 33,2 & 23,5 & 24,1 & 15,6 \\
\hline Chorotega & 59,4 & 51,5 & 44,1 & 42,3 & 20,5 \\
\hline Pacífico Central & 43,2 & 41,9 & 33,5 & 36,4 & 28,4 \\
\hline Brunca & 48,0 & 51,6 & 44,3 & 39,7 & 26,3 \\
\hline Huetar Atlántica & 33,2 & 29,2 & 29,0 & 29,3 & 24,2 \\
\hline Huetar Norte & 42,1 & 40,3 & 32,9 & 31,0 & 23,4 \\
\hline Zona & & & & & \\
\hline Urbana & 30,9 & 29,7 & 24,4 & 26,6 & 19,0 \\
\hline Rural & 40,8 & 39,4 & 33,0 & 30,5 & 18,7 \\
\hline Fuente: Elaracion & & & & \\
\hline
\end{tabular}

Fuente: Elaboración propia, sobre la base de la serie de pobreza 8.

Este resultado no es un tema menor y cobra especial importancia al analizar la variación de los hogares pobres según la estructura familiar. Entre 1987 y 1994, cerca del 70\% de los hogares pobres estaba encabezado por hombres que tenían pareja, mientras apenas el 2\% estaba encabezado por mujeres con pareja. El segundo grupo en orden de importancia correspondía a las mujeres solas (jefas de hogar sin pareja), que representaban el 19\%. 
Esa estructura cambió en 2017, pues disminuyó la proporción de hogares pobres encabezados por hombres y se duplicó la de aquellos encabezados por mujeres solas. Si se tiene en cuenta que este grupo es precisamente el de mayor incidencia histórica de la pobreza, resulta evidente que la vulnerabilidad de los hogares a cargo de una mujer sola es mucho más alta que la de cualquier otro tipo de hogar.

La educación es otro factor fuertemente asociado con la probabilidad de ser pobre. De hecho, el clima educativo del hogar es una variable con alto poder predictivo de este fenómeno. El clima educativo del hogar se refiere al promedio de años de estudio de los adultos que viven en el mismo hogar. En Costa Rica se habla de un clima educativo bajo cuando este promedio es inferior a 6 años de estudio (educación primaria incompleta), de clima educativo medio cuando el promedio se sitúa entre 6 y 11 años, y de clima educativo alto cuando la escolaridad de los adultos de un hogar es superior a 11 años (al menos secundaria completa).

En el gráfico 5 se muestra el porcentaje de hogares que tenían un clima educativo bajo según la condición de pobreza de los hogares. Así, se observa que, en 1987, casi el 80\% de los hogares en situación de pobreza extrema y cerca del $70 \%$ de los hogares en situación de pobreza no extrema tenían un bajo clima educativo. Si bien los hogares no pobres se ven menos afectados por problemas de escolaridad, la mitad de esos hogares también tenía un bajo clima educativo en 1987.

\section{Gráfico 5}

Costa Rica: distribución de los hogares con clima educativo bajo según la condición de pobreza, años seleccionados

(En porcentajes)

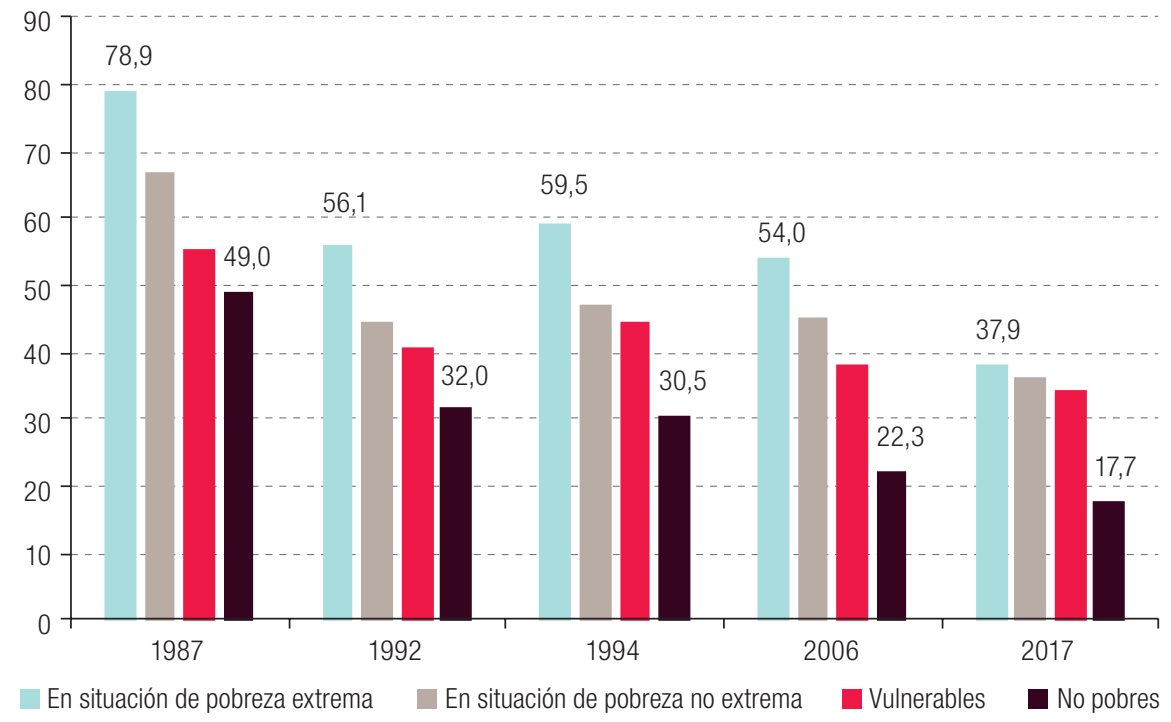

Fuente: Elaboración propia, sobre la base de datos del Instituto Nacional de Estadística y Censos (INEC) de Costa Rica.

Ya en 1992 se aprecia una notable disminución de la proporción de hogares con bajo clima educativo, pero que aún afectaba a la mitad de los hogares en situación de pobreza. Esta situación se mantuvo hasta 2006. Los efectos positivos del aumento de la cobertura educativa de Costa Rica en los últimos años resultan más evidentes en 2017: en promedio, solo el 36\% de los hogares pobres tenía un bajo clima educativo (muchos habían avanzado a la categoría de clima educativo medio) y menos de la quinta parte de los hogares no pobres aún presentaba esa condición.

En el gráfico 5 también se evidencia que la escolaridad ha mejorado de forma más veloz en los extremos de la distribución de ingreso. De hecho, el promedio de años de estudio de los jefes de los 
hogares en situación de pobreza extrema pasó de 3,7 años en 1987 a 5,9 años en 2017 (un crecimiento del 60\%). En los hogares en situación de pobreza no extrema ese promedio aumentó apenas de 5,2 a 5,9 años (el mismo alcanzado por los más pobres), mientras en los hogares no pobres la escolaridad media de los jefes de hogar aumentó de 7,1 años en 1987 a 9,1 en 2017 (un incremento del 29\%).

En general, la incidencia de la pobreza es mayor en los hogares con jefatura femenina, los hogares con jefes de mayor edad, los hogares de las zonas rurales y, en particular, en las regiones costeras o fronterizas. En el cuadro 3 se resume la incidencia de la pobreza monetaria para distintos grupos poblaciones en los años estudiados.

\section{Conclusiones}

El método oficial de medición de la pobreza monetaria en Costa Rica presenta algunas limitaciones a la realización de un estudio a largo plazo de la evolución de la pobreza, ya que por diversos motivos las series oficiales no son comparables entre los períodos 1987-1999, 2000-2009 y 2010-2017.

Uno de estos motivos se relaciona con la medición de los ingresos y con la manera en que esta ha cambiado a lo largo del tiempo, hasta contar en la actualidad con una medición mucho más precisa y detallada de los distintos ingresos que perciben los miembros de un hogar.

Asimismo, la construcción de la canasta básica de alimentos y el cálculo final de su valor en un año determinado están sujetos a la precisión con que se recolectaron los datos de gasto en la encuesta de ingresos y gastos del período respectivo (que mejora con cada nueva aplicación) y, principalmente, se basa en el supuesto de que esta canasta de bienes y servicios representativa se mantiene invariable durante varios años consecutivos.

Otros motivos se relacionan con aspectos metodológicos y estadísticos de los datos, que suponen la aplicación de distintos procedimientos en caso de valores faltantes en la composición del ingreso o ajuste por la posible subdeclaración de ingresos por parte de los informantes de cada hogar.

Para superar estas limitaciones, en este estudio se reconstruye la serie de ingreso per cápita del hogar para poder comparar los datos correspondientes a los distintos años (o al menos reducir el sesgo en la medida de lo posible), se propone una reconstrucción del valor de la canasta básica de alimentos (y por ende, de la línea de pobreza) y se evalúan los escenarios de imputación de ingresos y ajustes de subdeclaración siguiendo la metodología del INEC, con el objetivo de estudiar la evolución de la pobreza en el período 1987-2017.

Mediante la combinación de las series de insumos descritas anteriormente, fue posible estimar ocho series de pobreza distintas, con las cuales se logra demostrar la tendencia a la reducción de la pobreza en el período 1987-2017. Este resultado del análisis de la pobreza a partir de una serie de datos comparables en el tiempo es consistente en las ocho series de pobreza propuestas.

Al analizar la serie de pobreza que más se asemeja a la obtenida con la metodología oficial utilizada por el INEC, los resultados muestran que, a diferencia de lo que se cree, la incidencia de la pobreza no se estancó entre 1994 y 2017, sino que se redujo considerablemente. De acuerdo con la medición propuesta, en promedio la pobreza en Costa Rica disminuyó de un 29\% en 1997 a un 23\% en 2007, para luego reducirse ulteriormente hasta alcanzar el 19\% en 2017.

No obstante, esta reducción no fue sostenida a lo largo todo el período: entre 1994 y 2006 se registró en efecto un estancamiento, que se revirtió a partir de ese último año. Por esta razón, el nivel de pobreza en Costa Rica no solo no se estancó en las últimas dos décadas sino que, por el contrario, se redujo en una tercera parte con respecto a 1994. Este logro es aún más importante al considerar que la mayor disminución corresponde a la pobreza extrema. 
Por último, cabe realizar tres observaciones sobre los cambios implementados por el INEC en la metodología oficial de medición de la pobreza. En primer lugar, el objetivo de los cambios es mejorar la precisión de la medición de la pobreza en Costa Rica. En segundo lugar, los cambios fueron explicados ampliamente por parte del INEC. En tercer lugar, el INEC ha sido cuidadoso en no presentar los datos oficiales como si fueran una serie comparable para todo el período 1997-2017. Han sido otras entidades y personas las que han reunido e interpretado los datos no comparables como si lo fueran, a pesar de las advertencias del INEC.

\section{Bibliografía}

Acock, C. y D. Demo (2005), "Working with missing values", Journal of Marriage and Family, vol. 67, noviembre. Fernández, A. y R. Del Valle (2017), "Factores explicativos de la reducción de la pobreza por línea de ingreso y de la pobreza multidimensional en Costa Rica del año 2015 al 2016: un estudio de panel”, San José, Programa Estado de la Nación.

_ (2016), "Estimación del Índice de Pobreza Multidimensional de Costa Rica para el período 2005-2015. Sexto Informe del Estado de la Educación", San José, Programa Estado de la Nación.

Hidalgo, J. (2014), Crecimiento económico sin reducción de pobreza: el caso de Costa Rica, CATO Institute. INEC (Instituto Nacional de Estadística y Censos) (2018), Encuesta Nacional de Hogares 2018: creación de variables, San José,

(2015a), Encuesta Nacional de Hogares, julio 2015: resultados generales, San José.

(2015b), Índice de Pobreza Multidimensional (IPM): metodología, San José, octubre.

(2010a), Nueva Encuesta Nacional de Hogares 2010: descripción de los principales resultados, San José.

(2010b), "Nueva Encuesta Nacional de Hogares: actualización metodológica para la medición del empleo y la pobreza", Boletín Técnico, San José, noviembre.

- (2004), "Medición de la pobreza. Método de la línea de pobreza".

(2002), Encuesta de Hogares de Propósitos Múltiples: ajustes metodológicos en la EHPM, San José.

Medina, F. y M. Galván (2007), "Imputación de datos: teoría y práctica", serie Estudios Estadísticos, № 54 (LC/L.2772-P), Santiago, Comisión Económica para América Latina y el Caribe (CEPAL).

PEN (Programa de Estado de la Nación) (2017), Estado de la nación en desarrollo humano sostenible, San José. Ravallion, M. (2016), The Economics of Poverty: History, Measurement and Policy, Oxford University Press. Sauma, P. y J. Trejos (2010), "Evolución de la pobreza en Costa Rica: una revisión de las estimaciones 1980-1998", La pobreza en Costa Rica, Instituto de Investigaciones en Ciencias Económicas (IICE). 


\section{Anexo A1}

Cuadro A1.1

Costa Rica: series de pobreza estimadas mediante metodología comparable, 1987-2017

(En porcentajes)

\begin{tabular}{|c|c|c|c|c|c|c|c|c|c|}
\hline \multicolumn{10}{|l|}{ Detalles de la serie: } \\
\hline \multirow[b]{2}{*}{ Ingresos } & & \multicolumn{8}{|c|}{ Encuesta de Hogares de Propósitos Múltiples (EHPM) } \\
\hline & & EHPM & EHPM & EHPM & EHPM & EHPM & EHPM & EHPM & EHPM \\
\hline Imputación de ingresos faltantes & & No & No & No & No & Sí & Sí & Sí & Sí \\
\hline $\begin{array}{l}\text { Valor de la canasta básica de } \\
\text { alimentos y la línea de pobreza }\end{array}$ & & 1995 & 1995 & 2011 & 2011 & 1995 & 1995 & 2011 & 2011 \\
\hline Ajuste por subdeclaración de ingresos & & No & Sí & No & Sí & No & Sí & No & Sí \\
\hline Año & Oficial & Serie 1 & Serie 2 & Serie 3 & Serie 4 & Serie 5 & Serie 6 & Serie 7 & Serie 8 \\
\hline 1987 & 29,00 & 40,22 & 29,83 & 52,62 & 40,78 & 35,48 & 25,90 & 47,28 & 36,70 \\
\hline 1988 & 28,40 & 38,96 & 28,23 & 51,43 & 39,64 & 34,38 & 24,30 & 47,13 & 34,93 \\
\hline 1989 & 28,30 & 39,47 & 28,60 & 52,72 & 40,34 & 33,49 & 23,24 & 48,31 & 34,18 \\
\hline 1990 & 27,40 & 37,95 & 27,49 & 50,22 & 37,82 & 35,04 & 24,84 & 49,52 & 36,10 \\
\hline 1991 & 31,90 & 42,65 & 31,91 & 55,75 & 44,29 & 36,09 & 26,59 & 47,46 & 37,19 \\
\hline 1992 & 29,40 & 40,20 & 29,37 & 52,42 & 40,79 & 34,75 & 25,26 & 45,76 & 35,32 \\
\hline 1993 & 23,20 & 33,50 & 23,16 & 45,79 & 34,51 & 27,93 & 19,18 & 38,62 & 28,74 \\
\hline 1994 & 20,00 & 30,01 & 19,96 & 41,22 & 30,50 & 26,51 & 17,53 & 36,87 & 26,94 \\
\hline 1995 & 20,10 & 29,59 & 20,38 & 41,05 & 29,69 & 26,24 & 17,92 & 36,53 & 26,29 \\
\hline 1996 & 21,50 & 31,90 & 21,50 & 43,21 & 31,90 & 28,47 & 19,09 & 38,91 & 28,55 \\
\hline 1997 & 20,70 & 31,12 & 20,71 & 42,89 & 30,98 & 28,54 & 18,58 & 40,07 & 28,56 \\
\hline 1998 & 19,70 & 28,03 & 19,09 & 38,52 & 27,97 & 26,88 & 18,19 & 37,25 & 26,99 \\
\hline 1999 & 20,60 & 31,55 & 20,64 & 43,09 & 31,98 & 28,79 & 18,75 & 39,96 & 29,38 \\
\hline 2000 & 20,60 & 29,08 & 20,57 & 40,49 & 30,72 & 27,35 & 19,31 & 38,50 & 29,05 \\
\hline 2001 & 20,30 & 28,39 & 20,32 & 38,45 & 29,09 & 25,62 & 18,16 & 35,17 & 26,36 \\
\hline 2002 & 20,60 & 28,88 & 20,61 & 39,18 & 29,88 & 25,98 & 18,44 & 35,79 & 26,97 \\
\hline 2003 & 18,50 & 26,06 & 18,54 & 36,53 & 27,12 & 24,42 & 17,31 & 34,62 & 25,48 \\
\hline 2004 & 21,70 & 29,67 & 21,72 & 40,78 & 31,06 & 27,74 & 20,13 & 38,27 & 29,08 \\
\hline 2005 & 21,20 & 29,65 & 21,22 & 38,07 & 28,22 & 28,52 & 20,28 & 36,75 & 27,10 \\
\hline 2006 & 20,20 & 28,21 & 20,24 & 38,09 & 28,58 & 26,94 & 19,28 & 36,60 & 27,30 \\
\hline 2007 & 16,70 & 25,14 & 16,73 & 33,43 & 24,00 & 23,90 & 15,86 & 32,05 & 22,77 \\
\hline 2008 & 17,70 & 26,65 & 17,69 & 32,62 & 22,86 & 24,96 & 16,56 & 30,64 & 21,47 \\
\hline 2009 & 18,50 & 26,76 & 18,49 & 31,07 & 22,16 & 25,96 & 17,86 & 30,21 & 21,46 \\
\hline 2010 & 21,21 & 24,02 & 16,69 & 29,48 & 21,01 & 22,59 & 15,65 & 27,74 & 19,78 \\
\hline 2011 & 21,65 & 24,03 & 17,44 & 28,99 & 21,31 & 22,83 & 16,49 & 27,59 & 20,21 \\
\hline 2012 & 20,57 & 23,65 & 16,23 & 28,34 & 20,48 & 22,10 & 15,05 & 26,50 & 19,13 \\
\hline 2013 & 20,70 & 24,73 & 17,25 & 28,95 & 21,27 & 22,34 & 15,43 & 26,32 & 19,15 \\
\hline 2014 & 22,37 & 27,75 & 20,43 & 31,99 & 23,84 & 23,76 & 17,19 & 27,64 & 20,31 \\
\hline 2015 & 21,73 & 24,97 & 18,60 & 29,56 & 21,74 & 22,97 & 16,99 & 27,33 & 19,96 \\
\hline 2016 & 20,53 & 23,14 & 16,63 & 27,66 & 20,62 & 21,65 & 15,50 & 26,02 & 19,22 \\
\hline 2017 & 20,03 & 22,59 & 15,46 & 26,66 & 19,56 & 21,82 & 14,85 & 25,70 & 18,91 \\
\hline
\end{tabular}

Fuente: Elaboración propia, sobre la base de datos estimados según distintas combinaciones de parámetros. 


\section{Anexo A2}

Cuadro A2.1

Costa Rica: estimación de regresiones bivariadas

para analizar la tendencia de la pobreza por subperíodos, 1987-2017

\begin{tabular}{|c|c|c|c|c|c|c|}
\hline \multicolumn{7}{|c|}{ A. Subperíodo 1987-1992 } \\
\hline Serie & Coeficiente & Valor $p$ & $\mathrm{R} 2$ & $\begin{array}{c}\text { Significancia } \\
\text { global }\end{array}$ & $\begin{array}{l}\text { Magnitud } \\
\text { del efecto }\end{array}$ & $\begin{array}{c}\text { Significancia } \\
\text { global }\end{array}$ \\
\hline Oficial & 0,4010 & 0,4307 & 0,1608 & & & No \\
\hline Serie 1 & 0,3151 & 0,5430 & 0,0993 & & & No \\
\hline Serie 2 & 0,2768 & 0,5954 & 0,0766 & & & No \\
\hline Serie 3 & 0,2741 & 0,5991 & 0,0751 & & & No \\
\hline Serie 4 & 0,2910 & 0,5758 & 0,0847 & & & No \\
\hline Serie 5 & 0,0935 & 0,8601 & 0,0088 & & & No \\
\hline Serie 6 & 0,2051 & 0,6966 & 0,0421 & & & No \\
\hline Serie 7 & $-0,3377$ & 0,5126 & 0,1141 & & & No \\
\hline Serie 8 & $-0,0526$ & 0,9211 & 0,0028 & & & No \\
\hline \multicolumn{7}{|c|}{ B. Subperíodo 1994-2006 } \\
\hline Serie & Coeficiente & Valor $p$ & $\mathrm{R} 2$ & $\begin{array}{c}\text { Significancia } \\
\text { global }\end{array}$ & $\begin{array}{l}\text { Magnitud } \\
\text { del efecto }\end{array}$ & $\begin{array}{c}\text { Significancia } \\
\text { global }\end{array}$ \\
\hline Oficial & 0,0624 & 0,8395 & 0,0039 & & & No \\
\hline Serie 1 & $-0,4789$ & 0,0978 & 0,2294 & & & No \\
\hline Serie 2 & 0,0512 & 0,8682 & 0,0026 & & & No \\
\hline Serie 3 & $-0,6439$ & 0,0175 & 0,4146 & *** & 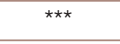 & Sí \\
\hline Serie 4 & $-0,4552$ & 0,1181 & 0,2072 & & & No \\
\hline Serie 5 & $-0,0893$ & 0,7717 & 0,0080 & & & No \\
\hline Serie 6 & 0,5407 & 0,0564 & 0,2924 & & $* * \star$ & No \\
\hline Serie 7 & $-0,2915$ & 0,3338 & 0,0850 & & & No \\
\hline Serie 8 & $-0,0404$ & 0,8956 & 0,0016 & & & No \\
\hline \multicolumn{7}{|c|}{ C. Subperíodo 1992-1994 } \\
\hline Serie & Coeficiente & Valor $p$ & $\mathrm{R} 2$ & $\begin{array}{c}\text { Significancia } \\
\text { global }\end{array}$ & $\begin{array}{l}\text { Magnitud } \\
\text { del efecto }\end{array}$ & $\begin{array}{c}\text { Significancia } \\
\text { global }\end{array}$ \\
\hline Oficial & $-0,9834$ & 0,0464 & 0,9672 & 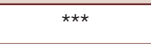 & $\star \star \star ~$ & Sí \\
\hline Serie 1 & $-0,9840$ & 0,0456 & 0,9682 & 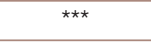 & $* * *$ & Sí \\
\hline Serie 2 & $-0,9834$ & 0,0464 & 0,9672 & 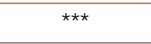 & 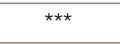 & Sí \\
\hline Serie 3 & $-0,9947$ & 0,0262 & 0,9895 & 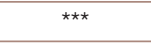 & *** & Sí \\
\hline Serie 4 & $-0,9918$ & 0,0326 & 0,9837 & 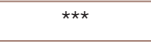 & $* \star *$ & Sí \\
\hline Serie 5 & $-0,9212$ & 0,0443 & 0,8486 & $\star * \star *$ & $\star \star \star *$ & Sí \\
\hline Serie 6 & $-0,9431$ & 0,0431 & 0,8895 & 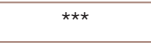 & *** & Sí \\
\hline Serie 7 & $-0,9298$ & 0,0480 & 0,8646 & 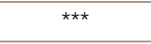 & *** & Sí \\
\hline Serie 8 & $-0,9390$ & 0,0447 & 0,8818 & 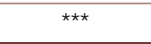 & 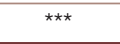 & Sí \\
\hline \multicolumn{7}{|c|}{ D. Subperíodo 2006-2017 } \\
\hline Serie & Coeficiente & Valor $p$ & $\mathrm{R} 2$ & $\begin{array}{c}\text { Significancia } \\
\text { global }\end{array}$ & $\begin{array}{l}\text { Magnitud } \\
\text { del efecto }\end{array}$ & $\begin{array}{c}\text { Significancia } \\
\text { global }\end{array}$ \\
\hline Oficial & 0,5662 & 0,0550 & 0,3206 & & 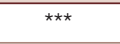 & No \\
\hline Serie 1 & $-0,5888$ & 0,0440 & 0,3467 & 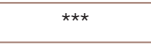 & 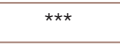 & Sí \\
\hline Serie 2 & $-0,3017$ & 0,3406 & 0,0910 & & & No \\
\hline Serie 3 & $-0,7915$ & 0,0022 & 0,6265 & 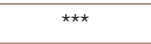 & *** & Sí \\
\hline Serie 4 & $-0,6861$ & 0,0138 & 0,4707 & 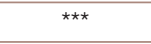 & $* \star *$ & Sí \\
\hline Serie 5 & $-0,7650$ & 0,0037 & 0,5852 & 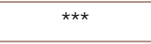 & $* \star * *$ & Sí \\
\hline Serie 6 & $-0,5339$ & 0,0438 & 0,2851 & 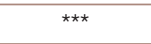 & 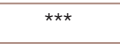 & Sí \\
\hline Serie 7 & $-0,8538$ & 0,0004 & 0,7290 & 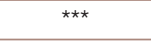 & 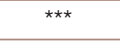 & Sí \\
\hline Serie 8 & $-0,7709$ & 0,0033 & 0,5942 & 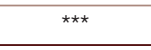 & 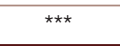 & Sí \\
\hline
\end{tabular}

Fuente: Elaboración propia.

Nota: ${ }^{* \star \star}$ El coeficiente tiene significancia estadística (valor p inferior a 0,05) o un efecto considerable (un valor del coeficiente estandarizado superior a 0,5 en valor absoluto). La significancia global se obtiene cuando el coeficiente cumple con ambas condiciones. 